* Artículos 



\section{Riendo entre tanto}

\section{Samuel Weber}

Este ensayo busca inicialmente dar cuenta del problema que ha sido la risa para Platón, Henri Bergson y Sigmund Freud. Específicamente, el autor aborda el vínculo que hay entre lo cómico y la risa en la obra freudiana El chiste y su relación con lo inconsciente, intentando mostrar la manera en que los chistes provocan risa articulando distintos aspectos psicoanalíticos y destacando la importancia de la temporalidad verbal del discurso en la operación existente en los chistes y cómo producen risa.

Palabras Clave: risa, chiste, inconsciente.

This essay deals with the issue of laughter in Plato, Henri Bergson, and Sigmund Freud. Specifically, the author analyses the relationship between the comic and laughter presented by Freud in his work Jokes and Their Relation to the Unconscious, showing how jokes evoke laughter through a series of different psychoanalytic aspects and also displaying the importance of verbal tenses in discourse by revealing how do they work and produce laughter.

KeY wORDS: laughter, joke, unconscious.

Fecha de recepción: 29 de marzo de 2010

Fecha de aceptación: 7 de abril de 2010 

Samuel Weber

Northwestern University, Evanston

\section{Riendo entre tanto ${ }^{1}$}

Traducción del inglés de Renato Huarte Cuéllar con ayuda de Daniel Stern

En el Prefacio a su pequeño libro sobre La risa (Le Rire: essai sur la signification du comique), Bergson explica por qué ha decidido no incluir un estudio comprehensivo y una discusión crítica de la literatura previa que versaba sobre el tema: "Nos parecía que esto complicaría excesivamente nuestra exposición, y necesitaría un volumen fuera de proporción dada la importancia del tema tratado". ${ }^{2}$ Bergson escribió esta nota en 1924, veinticinco años después de que hubiera publicado sus tres artículos en la Revue de Paris. El hecho de que su libro hubiera tenido en el ínterin veintitrés ediciones no alteró la ambivalencia de Bergson hacia esta cuestión, "este pequeño problema", como lo expuso él, que ha intrigado "a los más grandes pensadores desde Aristóteles", y que "siempre elude sus esfuerzos, se resbala, solo

\footnotetext{
${ }^{1}$ Este artículo fue publicado inicialmente como "Laughing on the Meanwhile", Modern Language Notes, 102, 2, French Issue (Sep. 1987), 691-706 [Nótese que en inglés se juega con la palabra mean, significar, en el título además del sentido de "mientras tanto"; N. del T.].

${ }^{2}$ Henri Bergson, Le Rire, Paris, Presses Universitaires de France, 1950. Las referencias a este artículo aparecerán de aquí en adelante en el texto como Rire.
} 
para reaparecer, como un reto impertinente lanzado a la especulación filosófica" (Rire, 1). En vista de la historia de este reto, Bergson justifica su propio esfuerzo señalando que no "buscará encerrar" su objeto "en una definición", sino más bien, meramente "observar cómo crece y se desarrolla". Aproximadamente ciento cincuenta páginas más adelante, Bergson concluirá sus observaciones comparando la risa con la "espuma" que se forma en la superficie del mar y que "traza la forma movible de su turbulencia":

A veces las olas que retroceden dejan un poco de su espuma en la arena de la playa. El niño jugando cerca levanta entre sus manos un puñado y se sorprende después de un momento al descubrir que todo lo que tiene en su mano son algunas gotas de agua, pero que son mucho más saladas y también más amargas que la ola que las trajo (152).

Bergson concluye diciendo que, como el niño, el filósofo que busca reunir algo de la "alegría" y la chispa de esta espuma curiosa "encontrará a menudo, a cambio de una pequeña cantidad de materia, una cierta dosis de amargura" (153).

¿Acaso el filósofo reconoce al final de su estudio que la materialidad insustancial peculiar de la risa es lo que explica la “amargura"? En cualquier caso, tal desconfianza de la risa, sea como tema serio o revulsivo, es tan vieja como el pensamiento occidental mismo. En el Libro III de la República, poco antes de la famosa discusión en torno a la mímesis, Sócrates aborda la cuestión de la risa, en particular como es mostrada por Homero. Su tratamiento del tema es tan sucinto como su conclusión inequívoca:

- No obstante, no conviene que los guardianes sean gente pronta para reírse [philógelos], ya que, por lo común, cuando alguien se abandona a una risa violenta, esto provoca a su vez una reacción violenta. 
- Me parece que sí.

-Por consiguiente, es inaceptable que se presente a hombres de valía dominados por la risa, y mucho menos si se trata de dioses.

-Por cierto.

-En tal caso, tampoco aceptaremos a Homero cosas como éstas acerca de los dioses:

e inextinguible allí se excitó la risa [ásbestos d'ar'enórto gélos] a los dioses felices, cuando, por sus casas, vieron a Hefesto afanarse.

(Ilíada I, 599-600)

- De acuerdo con tu argumento, no se puede aceptar esto.

- Mío será si me lo quieres adjudicar — repuse —; de todos modos, en efecto, no se puede aceptar.

(Platón, Diálogos, vol. IV, III, 388d-389a)

En este pasaje, el carácter ambivalente de la risa aparece con gran claridad: la risa es peligrosa para los guardianes del Estado, así como para todos los hombres de bien, por su tendencia a salirse de control. Esta tendencia, en cambio, deriva de la relación peculiar de la risa con el "sujeto": uno no se ríe de la manera en que uno camina o habla; no es un acto que el sujeto ejecute (o evite) a voluntad. En vez de decidir o escoger reírse, "uno se abandona a" la risa y ella es la necesidad del auto-abandono sin duda, que explica por qué la "condición" de la risa tendería a ser "violenta", así como también tendería a provocar "una reacción violenta". La risa es violenta y peligrosa, antes que nada, porque tiende a "subyugar" a aquellos que se ríen, especialmente si estos últimos son divinos $\mathrm{y}$, además, porque tiende a ser dirigida hacia otros. Por estas razones, la risa es peligrosa para los guardianes, y debe ser rechazada categóricamente (como la mímesis es rechazada generalmente en el mismo libro tercero). Para los dioses de Homero, la risa es tan "inextinguible" como una con- 
flagración, tan incontrolable como una enfermedad altamente contagiosa.

Finalmente, este breve pasaje de la República también es muy sugerente ya que une la violencia de la risa con el proceso de representación en general, y a la representación literaria en particular. La risa es peligrosa "en sí misma", pero la amenaza de controlar lo que ella conlleva parece particularmente virulenta cuando es representada en la literatura, especialmente en el discurso épico. Tendremos la ocasión de regresar a esto más adelante.

Si podemos no "aceptar" lo dicho por Homero, en donde el poeta representa dioses y hombres dominados por la risa, esto no necesariamente hace referencia al problema del tratamiento de la risa en sí misma, que no puede tan fácilmente ser desterrada de la República como los poetas. En las Leyes, Platón invoca una estrategia diferente:

Todo ciudadano debe decirse recordándoselo a sí mismo lo que es menos importante que esto y se dice a menudo, aunque no menos útil. Como cuando algo se aleja siempre es necesario que otra cosa se acerque en sentido contrario, así el recuerdo es afluencia de un pensamiento que se había alejado. Teniendo esto en cuenta, digo que hay que contener las risas violentas y lágrimas abundantes - todo varón debe recomendar esto a todo varón-e intentar guardar el tipo (VII, V, 732b-c).

La risa, al igual que las lágrimas, es un "desperdicio de sabiduría", una "emisión" que debe ser "balanceada" por una correspondiente "inmisión": aquella del "recuerdo"; o el recuerdo del "decoro", las reglas que "deben ser tomadas en mente por repetición". La aplicación de dichas reglas fue precisamente lo que Bergson había definido como la función social de la risa: a través de ella, argumentaba, la sociedad controlaba, a través de la humillación y la intimidación, las tendencias transgresivas de sus miembros. Platón, no obstante, está claramente menos se- 
guro de que, en palabras de Bergson, "la naturaleza ha colocado el mal al servicio del bien" (Rire, 152). Porque lo que obviamente preocupaba a Platón era la posibilidad de que el "decoro" se volviera, en sí mismo, "objeto" de la risa. La diferencia entre ambos pensadores podría tal vez ser medida de mejor manera por las figuras que usan para articular la risa. En el caso de Bergson, sin embargo, es la recurrencia regular de las olas, creando espuma en sus crestas y depositándolas en la playa. Platón, no obstante, describe la risa en términos de una "emisión" que parece más difícil de regular. El problema abordado es, en resumen, el control de las emisiones y la dificultad de resolverlo como lo conocemos hoy en día. También, precisamente en esos términos, la risa se impondrá en Freud cuando intente tratarla en su estudio sobre el chiste. Ahora quisiera abordar este texto.

Como es sabido, el libro de Freud excedió el mero intento de mostrar la calidad "insufriblemente ingeniosa" de los sueños que trajo a la luz La interpretación de los sueños. "El aparente ingenio de todos los procesos inconscientes", escribió Freud a Wilhelm Fließ en 1899, "está conectado muy de cerca con la teoría de los chistes y el humor" (Freud, The Origins, 297, carta 11/9/1899). El libro de 1905 es el intento por construir esa teoría.

A la luz de esto, la situación más bien inusual se desarrolla a través del esfuerzo de Freud por aceptar junto con el Witz: ${ }^{3}$ por un lado, la teoría pretendía demostrar que el ingenio puede ser producto del inconsciente $\mathrm{y}$, de esta manera, rebatir una objeción de Fließ - la primera de una larga lista de críticas que no cesó de cuestionar la legitimidad del psicoanálisis como ciencia - ${ }^{4}$ principalmente, que la interpretación de los sueños de Freud era, de hecho, solo una proyección de la ingenuidad del autor, enmascarada como una descripción de un objeto independiente. Por otra parte, desde el primer texto, Freud deja cla-

\footnotetext{
${ }^{3}$ Witz en alemán significa chiste [N. del T.].

${ }^{4}$ Cfr. Grünbaum, The Foundations.
} 
ro que cualquier teoría del Witz tendrá que coincidir con un fenómeno que tienda a poner en cuestión la posibilidad de tratar al chiste como algo independiente del objeto: la risa. Así como el sueño solo llega a ser dentro y a través de un proceso de reiteración mediante el cual es dislocado, desplazado y distorsionado (esto es: entstellt), del mismo modo el chiste solo es tal a través del efecto de la risa que produce, pero que, no obstante, también se constituye como si fuera, digamos, retroactivamente.

La comparación de la estructura retroactiva del sueño y del chiste, sin embargo, también indica el problema específico que confronta a Freud en su teoría del Witz: la Entstellung del sueño - a través de la repetición narrativa, así como a través de la "asociación" - opera en un medio que es isomórfico con el discurso verbal, que se encuentra articulado con la interpretación del sueño. En contraste, la Entstellung del chiste a través de la risa sitúa su "realización" o "logro" en un medio que, siendo no discursivo, es radicalmente diferente de aquel en que el chiste y su interpretación se manifiestan.

El esfuerzo de Freud por establecer una teoría del chiste se encuentra entonces confrontado con la necesidad de elaborar la relación de la risa con el Witz como Wortlaut. ${ }^{5}$ En tanto construcción verbal, el chiste puede depender en gran medida de los mismos mecanismos estilísticos ya descritos en relación con el "trabajo del sueño" (sobre todo la condensación y el desplazamiento); pero estos mecanismos, a partir de sí mismos, no pueden dar cuenta del poder del chiste para hacer reír.

En este punto, Freud no quiere comprometerse: un chiste que no hace reír, insiste, no puede ser considerado un chiste. Por lo tanto, para comprender el chiste teóricamente hay que apelar al problema de la risa. La intención inicial de Freud es "anexar" el

${ }^{5}$ Del alemán Wort: palabra, término, expresión y Laut: sonido, voz [N. del T.].

6 'dreamwork' tiene también el significado de "trabajo de ensueño" [N. del T.]. 
Witz a las formas indirectas de articulación presentadas por el inconsciente. Sobre todo en los sueños, el inconsciente se encuentra desplazado y tal vez incluso dislocado por la forma en que la risa se impone como el problema ineludible de "Der Witz und seine Beziehung zum Unbewußten". ${ }^{7}$

Antes de embarcarnos en tal discusión de este texto, no obstante, me gustaría agregar algo acerca de lo que justamente he llamado "la imposición" de la risa en el proyecto teórico freudiano de construir una teoría del Witz. Es poco rebatible que el enigma de la risa no fuera resuelto por Freud y que su recuento de él fuera de muchas maneras tanto parcial como insatisfactorio. Sin embargo, en un tiempo en que ha estado de moda "desmitificar" al psicoanálisis en nombre de la "realidad", que apela precisamente al grado que niega los conflictos y complejidades que le ocupaban a Freud, tal vez no sea superfluo señalar la forma en que su pensamiento rechaza la compulsión a sistematizar, esto es, la tentación de sacrificar la alteridad por la necesidad narcisista de la teoría. El que Freud estuviera constantemente al tanto de este peligro - tanto más poderoso por ser inevitablequeda claro a través de sus escritos. Estar al tanto de esta tentación teórica, "teóricamente", es una cosa; resistirlo en la práctica del propio pensamiento es, sin embargo, distinto. El tratamiento que Freud da a la risa en su libro sobre el Witz nos brinda una "lección objeto" de tal resistencia. El significado de esta "lección" residirá, por tanto, menos en el éxito de Freud al integrar la risa en su sistema psicoanalítico de conocimiento establecido previamente que en las formas en que la risa, incluso como está articulada, se resista a tal integración, obligando al "sistema" a dislocarse. Tal resistencia, sin embargo, no tendría jamás la posibilidad de articularse como lo hace - aunque sea de manera incompleta, inconsistente y sugestiva - si el pensamiento de Freud no estuviera abierto a la imposición de la alteridad

\footnotetext{
${ }^{7}$ Título original de El chiste y su relación con lo inconsciente [N. del T.].
} 
por encima y más allá de la inevitable necesidad de asimilar tal otredad a los límites conceptuales de un discurso cognitivo.

Permítasenos adentrarnos a la manera en que tal resistencia se manifiesta en el texto de Freud. Tal vez lo más impactante de esta aproximación al chiste no sea tanto la insistencia en que se le anexa, estructuralmente, por así decirlo, a la producción de la risa, sino más bien la manera en que Freud concibe la risa misma. La risa provocada por un chiste, enfatiza Freud, no es simplemente fuerte o incluso violenta; debe ser "explosiva". Esta determinación del fenómeno no es evidente por ella misma, no al menos porque pone en cuestión la propia fenomenalidad de la risa. ¿Es esto algo que irrumpe en un estallido, o más bien, como en el caso de la risa, no es meramente en un simple estallido (asumiendo por supuesto que tal estallido pueda ser singular), sino más bien en una serie de estallidos, aún identificable en términos de su fenomenalidad? Releamos el intento de Freud por lograr tal identificación:

Diríamos que la risa nace cuando un monto de energía síquica antes empleado en la investidura [catexis] ${ }^{8}$ de cierto camino psíquico ha devenido inaplicable, de suerte que puede experimentar una libre descarga ("El chiste", 140). ${ }^{9}$

[Wir würden sagen, das Lachen entstehe, wenn ein früher zur Besetzung gewisser psychischer Wege verwendeter Betrag von psychischer Energie unverwendbar geworden ist, so daß er freie Abfuhr erfahren kann] ("Witz", 164). ${ }^{10}$

\footnotetext{
${ }^{8}$ Se ha mantenido el término catexis del inglés y sus derivaciones a lo largo de la traducción para el término Besetzung. Cfr. Laplanche y Pontalis. Diccionario, 4953. En otras versiones puede encontrarse como "investidura" o "carga", como en la versión al castellano de Etcheverry [N. del T.].

${ }^{9}$ Freud. "El chiste y su relación con lo inconciente", en Obras completas, vol. VIII, trad. J. L. Etcheverry. Buenos Aires, Amorrortu, 1986. En las citas se recurrirá a esta traducción ya clásica en español y se hará referencia a esta como "El chiste" [N. del T.].

10 "Der Witz Und Seine Beziehung Zum Unbewussten", en Gesammelte Werke, vol. VI, Imago, London, 1940, 1-285; Jokes and their Relation to the Unconscious,
} 
Parecería aquí que Freud construye la risa como un fenómeno de forma directa y sincera, un fenómeno tal que pueda ser descrito de la manera siguiente: la energía que ha sido catectizada previamente es descatectizada y entonces "descargada libremente". Esta apariencia directa y sincera palidece, sin embargo, inclusive ante la más mínima reflexión en torno a la figuralidad enigmática de los términos empleados: no solo está el término "catexis" que en inglés tiene la dubitativa ventaja de solo poseer un significado técnico); sino también la "freie Abfuhr", generalmente traducido como "descarga libre". Comencemos entonces con un breve abordaje de estos dos términos. El punto de partida de la risa, su terminus ab quo, es una "catexis" establecida, esto es, el agregado de la cantidad de energía psíquica a una o más representaciones. Sobra decir que el término "catexis" — en alemán Besetzung - es uno de los más importantes y más elusivos en todo el pensamiento de Freud. Es uno de los más importantes ya que define, desde una perspectiva "económica", la condición mínima de la psique como tal. Además, Besetzung es uno de los términos más elusivos porque define dicha condición mínima como la dependencia del pensamiento representacional de factores que, a su vez, eluden una representación directa, incluyendo aquellos de la teoría que busca articular. Y muy probablemente no esté develando ningún secreto al decir anticipadamente que el encuentro del psicoanálisis con la risa poco aclarará las cosas: en el mejor de los casos aumentará considerablemente la complejidad del problema.

Teniendo en mente el hecho de que el término alemán Besetzung utilizado por Freud sugiere una ocupación militar, un sometimiento del enemigo, un aplaque de la resistencia, entre otros, estaríamos tentados a trazar el origen de la risa a un proceso en el que la ocupación sea, al menos temporalmente, neutralizada.

trad. J. Strachey, Harmondsorth, Pelican Freud Library, 1986. Las referencias a estas ediciones aparecerán a continuación en el texto como "Witz" y Jokes. 
En inglés, uno podría designar este proceso como "decathexis" (descatectización), pero la palabra alemana correspondiente es mucho más sugerente: la risa resulta de un proceso de Entsetzung. La palabra alemana es interesante por varios motivos, uno de ellos lo es particularmente ya que significa alivio: como cuando una guarnición tomada o una fortaleza ocupada (besetzten) es liberada, o cuando se levanta un sitio; menos benignamente tal vez, cuando un oficial es relevado de su cargo. El verbo más común en inglés para esto es: to be discharged. ${ }^{11}$ Como hemos visto, esta es precisamente la palabra utilizada por la Standard Edition $^{12}$ para traducir la Abfuhr alemana usada por Freud para designar la evacuación de energía que caracteriza a la risa. Esta coincidencia muestra la posibilidad de que tal descarga no sea clara o explícita en la argumentación de Freud, pero que conlleva, no obstante, a que el "levantamiento" temporal de la catexis no simplemente preceda a la "descarga libre", la freie Abfuhr que constituye la "risa" en el sentido propio del término, sino que puede coincidir con ella. Al colapsar (o condensar), la distinción diacrónica entre terminus ab quo: descatectización, y terminus ad quem descarga, el término Entsetzung, también indica por qué el tercer significado, el de estar sobrecogido con horror o terror, está relacionado con el proceso de la risa. Esto difícilmente será sorprendente si se recuerda que Freud, por lo menos en sus escritos de juventud, rastrea el origen de la ansiedad a la existencia de lo no catectizado, energía "libremente flotante", esto es, en una situación parecida a la condición atribuida a la risa. Pero si la similitud entre ambas pretende mostrar algo, la diferencia no se queda atrás. De ahí que haya razones para examinar tan cuidadosamente como nos sea posible lo que esa frase implica.

Al final del capítulo en el que Freud discute la risa, "El chiste como proceso social", termina su discusión anotando cómo ha

\footnotetext{
11 'discharged' tiene el sentido literal de quitar una carga pero también es la palabra para relevar de un cargo [N. del T.].

${ }^{12}$ Traducción del alemán al inglés de los textos de Freud.
} 
necesitado revisar su primera teoría "económica" del chiste. Según esta, el placer causado por el Witz es el resultado de una simple "economización" o reducción del "gasto" psíquico. Sin embargo, la necesidad de conciliar el papel de la risa con el proceso del chiste obliga a Freud a abandonar la perspectiva económica "restringida" (como lo hubiera dicho Bataille) desde donde buscaba explicar el chiste, a favor de una aproximación distinta:

Un ahorro localizado como el que acabamos de considerar nos deparará ineludiblemente un placer momentáneo, pero no podrá agenciarnos alivio duradero si lo aquí ahorrado puede hallar empleo en otro sitio [an anderer Stelle zur Verwendung kommen kann]. Solo si puede evitarse ese uso en otro lugar [diese anderweitige Verfügung], el ahorro especial vuelve a trasmudarse en un alivio general del gasto psíquico. Así, con una mejor intelección de los procesos psíquicos del chiste, el factor del alivio reemplaza al del ahorro [So tritt...das Moment den Erleichterung an die Stelle der Ersparung] ("El chiste", 150; "Witz", 176).

La“economía localizada... especializada" del llenado de cuentas balanceado y de doble entrada no basta para explicar el alivio duradero procurado por la risa que el chiste produce. La "libre descarga" no simplemente significa la "evacuación" o “eliminación” de la energía psíquica por medio de su transformación en pura "movilidad", por ejemplo movimiento físico. De lo que esta "descarga" debe estar libre, si ha de devenir en risa, es de cualquier tipo de Verwendung ${ }^{13}$ o Verfügung ${ }^{14}$ útiles: libre de cualquier nexo estable con metas, fines o cualquier otra representación. Esto, sin embargo, no significa que la "descarga libre" de la risa no tenga relación con dichas representaciones. Por el contrario, es solo en relación con ellas que la risa puede

\footnotetext{
${ }^{13}$ Uso o empleo [N. del T.].

${ }^{14}$ Disposición u orden [N. del T.].
} 
ser determinada para Freud. Esta relación, sin embargo, implica una discontinuidad que es irreductible $\mathrm{y}$, al mismo tiempo, generadora de pensamiento a partir de la representación. Y paradójicamente, esta discontinuidad generativa estará ligada con una particular forma de presentación.

Pero, a menos que me adelante, quiero regresar al texto de Freud para poder volver a andar sobre lo que he llamado su confrontación con el problema de la risa, o más bien, la forma en la que la risa se le impone. Si en el pasaje ya discutido, como en muchos otros, Freud describe la condición de la risa como "el levantamiento de las catexis previas" (véase "Witz", 166), el tipo de Besetzung que tiene en mente aquí no es ordinario: no es tanto una representación catectizada, sino más bien una contrarrepresentación catectizada, o lo que él llama Hemmungsbesetzung (167), y la Standard Edition llama "inhibitory cathexis" (Jokes, 201), que podría ser traducida como "catexis inhibitoria". ${ }^{15}$ La distinción entre representación y contra-representación no carece de importancia porque, de hecho, el establecimiento de cualquier catexis estable depende de una inhibición; esto es, al parar o contrarrestar la tendencia del proceso primario de cambiar desbocadamente de representación en representación. En este sentido, lo que se "levanta temporalmente" en el proceso del chiste y que constituye la condición de la risa no es simplemente la catexis de una representación particular o de un conjunto de representaciones, sino la contra-fuerza inhibitoria que es el principio de representación en sí mismo según Freud. Sin algún tipo de "inhibición” o Hemmung, unidad que no se representa, no hay Denkidentität ${ }^{16}$ (y probablemente tampoco una Wahrnehmungsidentität ${ }^{17}$ ) que sea concebible. ${ }^{18}$

\footnotetext{
${ }^{15}$ O según la traducción de Etcheverry "investidura inhibitoria" [N. del T.].

${ }^{16}$ Identidad del pensamiento [N. del T.].

${ }^{17}$ Identidad de percepción [N. del T.].

${ }^{18}$ Véase la discusión de Hemmung en mi Legend of Freud, 33.
} 
Aproximadamente diez años después del libro sobre los chistes, en su ensayo sobre Lo inconsciente (1913), Freud señalaba que "toda vez que a un tal proceso primario le es permitido jugar con elementos del sistema Prcc, aparece como 'cómico' y mueve a risa" ("Lo inconsciente", 183-184). ${ }^{19}$ En el proceso primario, el proceso inhibitorio se encuentra en su punto más débil: de aquí que produzca risa. La risa comparte con la ansiedad esta tendencia de desbordar la inhibición.

Entonces, lo que fue "levantado" o "suspendido" en el proceso del chiste no es simplemente una catexis particular, sino la condición inhibitoria de la catexis misma. Esto puede servir para explicar la insistencia de Freud en la naturaleza "explosiva" 20 de la risa ocasionada por el Witz: lo que explota es la fuerza inhibitoria indispensable para cualquier proceso psíquico de síntesis. Lo que está en juego con tales “explosiones", entonces, es la habilidad para formar y mantener las representaciones "estables" o duraderas, incluyendo aquellas de las que el mundo de los sujetos y objetos depende.

Pero la "explosividad" no es la única característica que Freud le asigna a la risa: otro rasgo relacionado pero no idéntico es el de ser "automático"; para que la risa "explote", el chiste debe ser construido de forma tal que promueva un cierto grado de automatismo. La descripción freudiana de este proceso es de gran interés ya que toca lo que anteriormente describimos como el problema central de este estudio: la relación del Witz como una estructura discursiva con la ruptura de la discursividad impli-

\footnotetext{
${ }^{19}$ En el libro sobre los motivos del chiste, Freud hace una observación relacionada con esto: "Cualquier develamiento de material inconsciente... nos impacta en general como algo "cómico" [Any uncovering of unconscious material...strikes us in general as 'comic', Jokes, 228]. Y agrega, en una nota a pie de página, que muchos de sus pacientes se ríen "aun cuando el contenido de lo que es develado no lo justifica de manera alguna" ["even when the content of what is unveiled would by no means justify this"].

${ }^{20}$ También puede traducirse por "irruptiva”, como la lava de un volcán [N. del T.].
} 
cada en el estallido de la risa. Lo que esa risa requiere, Freud escribe, son las técnicas discursivas que

evidentemente sirven el propósito de restar por completo del proceso chistoso la atención del oyente, y hacer que transcurra de una manera automática. Digo adrede "automática" y no "inconsciente", pues esta última designación sería errónea. Aquí sólo se trata de mantener alejado [fernzuhalten] del proceso psíquico que sobreviene cuando se escucha el chiste el plus de investidura [catexis] de atención; y la utilidad de estas técnicas auxiliares nos da derecho a conjeturar que precisamente la investidura [catexis] de atención desempeña un considerable papel tanto en la supervisión como en el nuevo empleo de una energía de investidura [catectizada] liberada ("El chiste", 144145; "Witz", 204).

Las razones de Freud para distinguir el "automatismo" en el proceso del chiste de lo inconsciente son, por un lado, aparentes: el chiste no es un producto del inconsciente de la misma manera en que lo son los sueños. La conciencia no está ausente mientras se cuenta y escucha un chiste, está presente, pero de una manera muy peculiar, la presencia está al mismo tiempo "mantenida a lo lejos", ferngehalten, de lo que realmente "está pasando" en el chiste. En un cierto sentido, Freud da cuenta de la relación de lo consciente e inconsciente en general: desde la perspectiva de este último, los objetos de la conciencia generalmente tienen el carácter de una "formación substituta", una "contracatexis", que obtiene el lugar y sustituye la(s) representación(es) que ha(n) sido reprimida(s); esto se sostiene tanto para el síntoma como para el sueño. Esta es, sin lugar a dudas, la razón por la que el intento de Freud por establecer una diferencia clara y distinta entre lo "automático" y lo "inconsciente", en el cual recurre a los términos de su topografía psíquica, no sea particularmente convincente. En esta discusión del "proceso cómico" repite su argumentación que anteriormente había desarrollado respecto del Witz: 
[El proceso cómico] Más bien es nativo de lo preconsciente, y parece adecuado emplear el nombre de "automáticos" para los procesos que se juegan en lo preconsciente y escapan a la investidura [catexis] de atención a que va conectada la conciencia. El proceso de la comparación de los gastos debe permanecer automático si es que ha de producir placer cómico ("El chiste", 208; "Witz", 284).

Sin embargo, el automatismo cómico de "comparar gastos" no da cuenta del Witz que, como Freud deja claro, no puede ser asimilado a una economía restrictiva característica del ego. El único elemento común a ambos procesos, el cómico y el del chiste - y esto nos ayudará más adelante - es precisamente el hecho de que son procesos. No es la diversión de la atención consciente como tal que caracteriza la noción de "automatismo" en este texto. Lo que parece ser decisivo es aquello de lo que la conciencia es distraída: algo que está transcurriendo, un Vorgang $^{21}$ que tiene un Verlauf. ${ }^{22}$

En el Witz, entonces, algo está pasando de lo que no sabemos. Pero saber nada (knowing nothing), como veremos, no es necesariamente lo mismo que no saber nada (not knowing anything). Por el contrario, la condición del chiste es que al que escucha se le dé algo para que sepa, pero algo que al mismo tiempo no tenga nada que ver con lo que realmente está sucediendo. Como Freud dice, los chistes "emplean el artilugio de distraer la atención mostrando algo en su expresión que la fascina (sie fesselt), para que entre tanto (unterdes) la liberación de la catexis inhibitoria y su descarga puedan permanecer completamente imperturbadas" ("El chiste", 145; "Witz", 204). Lo que me parece de particular interés en su descripción es el pequeño vocablo alemán unterdes — “entre tanto/mientras tanto". El "automatismo" del chiste, sin duda relacionado a los

${ }^{21}$ Proceso [N. del T.].

${ }^{22}$ Circuito [N. del T.]. 
movimientos automáticos de aquella risa que en el proceso encuentra su consumación y confirmación, trae a colación la pregunta de la temporalidad del proceso del chiste; empezamos a sospechar que esto tal vez pueda tener la llave para el problema que nos ocupa: el de la relación entre la risa y el Witz como discurso verbal.

Por esto nos gustaría encontrar otro poco de este "entre tanto". Como Freud lo describe, el chiste usa sus técnicas variadas para cegar y divergir la atención consciente del que escucha: enigmas, alusiones u omisiones sirven a este propósito, pero

Más eficaces aún son las formaciones de una fachada [...]. Las fachadas silogísticas cumplen, de manera notable, el fin de retener la atención planteándole una tarea. Apenas comenzamos a reflexionar [während wir nachzudenken beginnen] que pueda tener esa respuesta cuando ya reímos; nuestra atención ha sido tomada por sorpresa, ya se consumó la descarga de qué resultó mal en la respuesta, ya nos estamos riendo; nuestra atención ha sido tomada por sorpresa [überrumpelt worden: sobrecogido], ya se consumó [ist vollzogen] la descarga de la investidura (catexis) inhibitoria liberada ("El chiste", 145; "Witz", 205).

Lo que llama más la atención de esta descripción es el uso de los tiempos verbales: todo parece estar situado dentro o alrededor del tiempo presente, y aun así, el tiempo presente describe un espacio que precisamente no está presente para la conciencia, al menos no en la forma de representación mental; en tanto hemos comenzado a pensar en lo que ha sucedido, "ya nos estamos riendo". Lo que ha pasado, por lo menos entre tanto, es la irrupción de la risa, presumiblemente en la manera en que Hegel justamente ha descrito en su Estética: "La risa en general es la irrupción de un brote (der Ausbruch des Herausplatzens), que sin embargo no debe permanecer desprovisto de la pertinencia si el ideal no ha sido perdido" (Hegel, Ästhetik, vol. I, 161). Pero el ideal está comprometido irremediablemente ya que nuestra 
atención ha sido überrumpelt: no simplemente "estar desatentos", como Strachey lo traduce, tampoco simplemente "overwhelmed" ("Sobrecogido"); la palabra alemana rumpeln significa, onomatopéyicamente, un ruido retumbante y resonante. La mente del que escucha ha sido sobrecogida por un sonido que la desorganiza; "llegamos hacia" y nos encontramos a nosotros mismos engullidos por la risa. Es simplemente imposible saber dónde y cómo la risa "comenzó": tan pronto comenzamos a recordar, nachzudenken, descubrimos que ya ha "pasado", de hecho por todo nuestro cuerpo que ya no cumple nuestra voluntad.

Todo esto aplica por completo solo al que escucha el chiste. Resulta interesante que Freud describe sucesos bastante similares aconteciendo del otro lado del proceso del chiste: no en el escuchar, ni siquiera al contar el Witz, sino en su "hacerse", aunque tal vez la expresión, resalta, no es tan apropiada para el proceso a través del cual el chiste emerge:

Y es que se dice: uno "hace" el chiste, pero siente [man verspürt] que su comportamiento es allí diverso de cuando formula un juicio o hace una objeción. El chiste posee, de manera sobresaliente, el carácter de una "ocurrencia involuntaria" [eines ungewollten Einfalls]. ${ }^{23}$ Un momento antes uno no sabe qué chiste hará, al que luego sólo le hace falta vestir con palabras. Más bien se siente algo indefinible que yo me inclinaría a comparar con una ausencia, un repentino cese [Auslassen] de la tensión intelectual, y hete aquí que el chiste brota de golpe [dann ist der Witz mit einem Schlag da], las más de las veces junto ya con su vestidura [gleichzeitg mit seiner Einkleidung] ("El chiste", 160-161; "Witz", 225).

${ }^{23}$ La palabra alemana Einfall, literalmente "caer dentro" significa tanto una "inspiración" o "idea" imprevisible como un ataque sorpresivo. Ungewollt quiere decir "no querido" e "involuntario". Strachey traduce al inglés: "una noción que se nos ha ocurrido involuntariamente" ["a notion that has occurred to us involuntarily"] (Jokes, 224). 
"Hacer" peculiarmente un chiste repite o anticipa el advenimiento de la risa, la ruptura que "hará" —o rehará- el chiste. El chiste recae sobre su "hacedor", así como en su "rehacedor", el que escucha. En ambos casos, el chiste y la risa no emergen gradualmente, no son producto de un proceso largo y continuo: más bien están simplemente "ahî", de repente, ya listos. El único signo que uno tiene para aproximarse es, en ausencia de signos, un cierto Auslassen, una palabra que Strachey traduce como "dejar ir", pero que sus contrapartes franceses, Marie Bonaparte y el Dr. M. Nathan, hacen mejor al dejarlo como déffaillance subite (Freud, Le Mot d'esprit, 278). El término Auslassen que Freud utiliza para caracterizar la "ausencia" que acompaña la llegada de un chiste no es meramente otra forma de "descarga" como un "dejar ir"; más bien implica no un "dejar salir" sino un repentino "dejar subir" de la manera en que un motor puede "morir" durante un cambio de velocidades. El chiste no se "deja ir" o "deja salir" por el simple hecho que nunca ha "permanecido dentro"; ein Einfall ${ }^{24}$ no es un Ausdruck. ${ }^{25}$ Más bien, Freud le atribuye al chiste como a la risa el carácter de regalo. Es bastante explícito sobre esto en el caso de la risa: el chiste es presentado al que escucha sin requerir virtualmente ningún esfuerzo por parte del escucha: "Es wird ihm sozusagen geschenkt" ("Witz", 166) que Strachey traduce como: "He might be said to have been presented with it" (Jokes, 201). ${ }^{26}$ Quiero insistir en el curioso carácter del "presente". ${ }^{27}$ lo que al que escucha se le presenta no es, como podría parecer, una mera representación que Freud llama una "verpönte Vorstellung", ${ }^{28}$ una "idea proscrita". Lo que es "dado" es el "levantamiento" o la "suspensión" de una inhibición y de la fuerza que lo sostiene.

\footnotetext{
${ }^{24}$ Un incidente [N. del T.].

${ }^{25}$ Expresión [N. del T.].

26 "Podría ser dicho que ha sido presentado [o dado] con él".

${ }^{27}$ No se pierda el sentido que "presente" tiene también como "regalo" [N. del T.].

${ }^{28}$ Literalmente una "representación tabú" [N. del T.].
} 
Es decir, la fuerza ya no sirve para mantener y consolidar la economía restringida de placer y representación. Lo que sustituye la catexis inhibitoria - de catexis como inhibición-es un cierto "dar" que, como podremos ver, no es simplemente lo otro o el opuesto al "tomar".

Pero no solo al que escucha se le presenta el chiste, al que lo cuenta también se le "da": hay un dejar subir en la tensión intelectual y, de pronto, súbitamente digamos, el chiste está ahí, dado, un regalo sin donador. El chiste es "presentado" al que lo cuenta de igual manera que al que lo escucha. El chiste, en resumen, es presentado a sus sujetos. Pero, para estar presente, ¿podría llegar de tal manera, podría arreglárselas de alguna manera para amainar la tensión intelectual, por su tendencia muy específica, tenor y sobre todo por su particular tiempo verbal?

Permítaseme intentar de manera breve mostrar qué tan importante es este tiempo verbal para el chiste citando dos traducciones de uno de los chistes citados por Freud como un ejemplo de chistes "sofisticados" haciendo uso de "errores lógicos" (Denkfehler) para tratar de mostrar mi posición. Les contaré el chiste primero en alemán, y después en el inglés de la Standard Edition de Strachey. Ya que todos han escuchado sin duda alguna el chiste miles de veces, lo podrán ver como un viejo amigo, sin la obligación de reírse (pero por supuesto que nadie nunca se ha reído con convencimiento - explosivamente - por pura obligación de cualquier forma). Aquí está entonces la versión alemana de un chiste sofisticado:

Ein Herr kommt in eine Konditorei und läßt sich eine Torte geben; bringt dieselbe aber bald wieder und verlangt an ihrer Statt ein Gläschen Likör. Dieses trinkt er aus und will sich entfernen, ohne gezahlt zu haben. Der Ladenbesitzer hält ihn zurück. "Was wollen Sie von mir?" - "Sie sollen den Likör bezahlen". — "Für den habe ich Ihnen ja die Torte gegeben". _." Die haben Sie ja auch nicht bezahlt". _-"Die habe ich ja auch nicht gegessen" ("Witz", 63). 
Y ahora, el "mismo" chiste en la Standard Edition:

Un señor entró a una cafetería y ordenó un pastel; pero pronto decidió cancelar y pedir un licor en su lugar. Se lo tomó y comenzó a salir sin haber pagado. El propietario lo detuvo. “¿Qué es lo que quiere?", dijo el cliente. - "Usted no ha pagado por el licor". — "Pero le di el pastel a cambio". _ "Usted tampoco ha pagado por el pastel". — "Pero no me lo he comido" (98). ${ }^{29}$

Desafortunadamente no es posible comprometerse más que con una adecuada interpretación de tan memorable chiste. Tal interpretación tendría que tomar en cuenta el hecho de que, en la versión alemana, el "cambio desigual" y la circulación comienza con una especie de "regalo": el patrón "läßt sich eine Torte geben", literalmente "le fue dado a él un pastel", termina con la sorprendente repetición involucrando las palabras ja, auch y nicht (sí, también y no). Ninguna de estas podría ser fácilmente puesta en inglés, sospecho. Lo que hubiera sido posible, y que de hecho la versión francesa hace, es reproducir el tiempo verbal del alemán que es, por supuesto, el tiempo presente. ${ }^{30}$ Digo "por supuesto" y sin embargo parece que no es del todo obvio para los responsables de la Standard Edition que cuentan el chiste (e incluso los sueños) en tiempo pasado; el chiste está formulado en una especie de pretérito épico o lo que se ha llamado "pasado absoluto", cuya función primaria es precisamente confinar lo que narra en una representación definitiva y cerrada: "Había una vez un señor que entró a una

\footnotetext{
${ }^{29}$ Etcheverry traduce al castellano el chiste: "Un señor llega a una confitería y se hace despachar una torta [un pastel]; pero enseguida la devuelve y en su lugar pide un vasito de licor. Lo bebe y quiere alejarse sin haber pagado. El dueño del negocio lo retiene. ‘¿Qué quiere usted de mí?'. - 'Debe pagar el licor'. - ‘A cambio de él ya le he dado la torta [el pastel]'. - 'Tampoco la ha pagado'. - 'Pero tampoco la he comido"" ("El chiste", 58) [N. del T.].

${ }^{30}$ Como hemos visto, la traducción al castellano de Etcheverry también respeta el tiempo presente [N. del T.].
} 
cafetería, comió un pastel y se fue sin pagar". Lo hizo, de una vez por todas, y esa es la historia contada en breve. El único problema con tal forma tan compacta de relatarlo, que podría servir muy bien para todo tipo de cuentos de hadas, protocolos y reportes — de hecho un reporte policial, siguiendo a un individuo-, es que este "pasado absoluto" no tiene absolutamente la oportunidad de generar una desorientación acústica, ese Überrumpelungseffekt ${ }^{31}$ que requiere la risa para brotar. O más bien, si nosotros vamos a estallar en carcajadas. Por el contrario, lo que se produce con el pasado absoluto es el placer del reconocimiento: “Ajá, intentó salirse con la suya, ¿no? Bueno, no funcionó...". Los chistes en tiempo pasado no "funcionan". Ya que, aunque el "pasado" pone al chiste en su lugar, la propiedad de ese lugar deja poco espacio para la risa.

En contraste, el ejemplo de la Standard Edition nos permite medir la capacidad de la importancia del tiempo presente usado tanto en Freud como en los traductores franceses. Y lo que es memorable acerca de este tiempo es el hecho de que es más próximo a nosotros y a la vez más alejado que el pretérito: "Un hombre entra a una cafetería y ordena un pedazo de pastel, pronto decide cancelarlo y pedir un vaso de licor en su lugar [...]". ¿Cuándo lo hace? ¿Cuándo deja de hacerlo? ¿Dónde lo hace? ¿Se sale con la suya? La historia contada en presente es imposible de localizar, tanto como la ocurrencia del chiste o el brote de la risa. Y es imposible de localizar porque su "presente" no es el de la representación, sino el del proceso de representarse " $a$ sí mismo" —que ha sido llamado de varias maneras: enunciación, pronunciación, iterabilidad- No es posible situar de una vez por todas porque su tiempo y lugar son inseparables de un movimiento que disloca el intercambio dialógico y, al hacerlo, abarca el "punto"- - un pointe cuya afirmación y negación son

\footnotetext{
${ }^{31}$ Efecto de irrupción [N. del T.].
} 
una repetición automática que escanea el ritmo contrapuntal del deseo: ja, ja auch nicht, ja auch nicht.

Pero esta repetición no es la que Freud le adscribe al chiste cuando busca construir su esencia como "juego": como la recuperación simple o reconocimiento de lo idéntico a través de sus variaciones (dudoso e indispensable momento en la constitución del ego). Más bien, la repetición en funcionamiento aquí está más próxima a la compulsión "demoníaca" que Freud más tarde llegará a designar como repetición-compulsión: una repetición que nunca cierra el círculo y que - en este chiste como en muchos otros - siempre involucra un intercambio desigual.

Es la repetición que "nos rompe" en una risa "explosiva" la que Freud ha intentado inscribir en su texto, con el riesgo de desarticular la propia teoría que ha estado tratando de elaborar. En lo que respecta al cuerpo, el reírse es mucho más difícil de asimilar a una economía y a una temporalidad de representación que a un cuerpo histérico que, como síntoma, sigue siendo significante. Riendo entre tanto, el cuerpo es dislocado, ent-stellt, pero también: insignificado/insignificante. Es en esta risa en que la Entstellung amenaza con salirse de control y dislocar el significado mismo del que el psicoanálisis se retira, no sin antes haber trazado los esbozos de un cuerpo que se presenta a sí mismo como el regalo equívoco de la materia risible.

\section{REFERENCIAS}

Bergson, Henri, Le Rire, Paris, Presses Universitaires de France, 1950. Freud, Sigmund, "DerWitzUnd Seine BeziehungZumUnbewussten", en Gesammelte Werke, vol. VI, London, Imago, 1940, 1-285.

- The Origins of Psychoanalysis, trad. James Strachey, New York, Basic Books, 1954.

__ , "El chiste y su relación con lo inconsciente", en Obras completas, vol. VIII, trad. J. L. Etcheverry, Buenos Aires, Amorrortu, 1986. 
FreUd, Sigmund, Le Mot d'esprit et ses rapports avec l'inconscient, Paris, Gallimard, 1969.

—, Jokes and their Relation to the Unconscious, trad. J. Strachey, Harmondsorth, Pelican Freud Library, 1986.

—_, "Lo inconsciente", en Obras completas, vol. XIV, trad. José L. Etcheverry, Buenos Aires, Amorrortu, 2003.

Grünbaum, Adolf, The Foundations of Psychoanalysis. A Philosophical Critique. Berkeley, University of California Press, 1984. Hegel, Georg Wilhelm Friedrich, Ästhetik, vol. I, Frankfurt am Main, Europäische Verlagsanstalt, 1955.

Laplanche y J. B. Pontalis, Diccionario de psicoanálisis, Barcelona, Labor, 1983.

Homero, Ilíada, trad. R. Bonifaz Nuño, México, Universidad Nacional Autónoma de México, 2005 (Bibliotheca Scriptorvm Graecorvm et Romanorvm Mexicana).

Platón, Diálogos. Vol IV. República, trad. C. Eggers Lan, Madrid, Gredos, 2008 (Biblioteca Clásica Gredos).

—, Diálogos VII. Leyes (Libros I-VI), trad. F. Lisi, Madrid, Gredos, 1999 (Biblioteca Clásica Gredos).

Weber, Samuel, Legend of Freud, Minneapolis, University of Minnesota Press, 1982. 